\title{
STUDI EVALUATIF PROGRAM PELATIHAN PEMBERDAYAAN MASYARAKAT DI BANK INDONESIA PROVINSI GORONTALO
}

\section{(Evaluative Study Community Empowerment Training Program In The Province of Bank Indonesia Gorontalo)}

\author{
Lia Nurhayati ${ }^{1}$ \\ ${ }^{1}$ Staf Dosen Program Studi Ekonomi Pembangunan, Universitas Muhammadiyah Gorontalo
}

Email : nurhayati.liaa@gmail.com

\begin{abstract}
This study is an evaluative studies that measurable the quality of community development training program in Indonesian Bank. Based on the result of observations show that the Indonesian Bank was instrumental in the karawo development. Which is a commodity in Gorontalo. Training conducted by Indonesian Banks are very diverse ranging from slicing and embroider karawo, business management through the creation of websites. Role in the development of Indonesian Banks karawo embroidered Festival Karawo shown in 2011 and 2012. This study uses the evaluation approach, the method CIPP (Context, Input, Process and Product). Context of this research is the Indonesian Bank policy as outlined in the vision and mission of the UMKM development. Program planning, program goals and objectieves which listed in the Indonesian Bank regulation No.14/22/PBI/2012. Input evaluations include : instructors, trainess, materials, facilities and infrastructure, financial resources. Process evaluation include implementation program and product evaluation provides for an increased production and marketing. Based on these evaluation measurable success of the training program. Expected result of the research can be useful for the writer himself and the Indonesian Bank as organizing training course.
\end{abstract}

Keyword: Training Program, Community Development, Indonesian Bank of Gorontalo

\section{PENDAHULUAN}

Masalah pembangunan merupakan masalah yang kompleks. Kompleksitas itu misalnya dari sisi manajemen berarti perlu dilakukan perencanaan, pelaksanaan, monitoring dan evaluasi. Dari sisi bidang yang harus dibangun juga memiliki aspek kehidupan yang sangat luas, aspek kehidupan itu mencakup kehidupan politik, ekonomi, sosial dan budaya serta pertahanan dan keamanan. Dalam pemerintahan yang otoriter yang sentralistis, dalam realitas masyarakat lebih diposisikan sebagai obyek pembangunan. Ketika kini pemerintahan yang demokratis yang hendak dikembangkan, maka ada perubahan posisi masyarakat yang semula lebih diposisikan sebagai obyek pembangunan menjadi subyek pembangunan.

Memposisikan masyarakat sebagai subyek dalam pembangunan agar bersifat efektif perlu dicarikan berbagai alternatif strategi pemberdayaan masyarakat. Konsep pemberdayaan menurut Usman (2004) menyatakan bahwa manusia adalah subyek dari dirinya sendiri, proses pemberdayaan yang menekankan pada proses memberikan kemampuan kepada masyarakat agar menjadi lebih berdaya, mendorong atau memotivasi individu agar mempunyai kemampuan dan keberdayaan untuk menentukan pilihan hidupnya, pemberdayaan harus ditujukan pada kelompok atau lapisan masyarakat yang tertinggal.

Pemberdayaan masyarakat dapat dilakukan oleh banyak elemen, seperti pemerintah, perguruan tinggi, lembaga swadaya masyarakat, pers, partai politik, masyarakat sipil atau organisasi masyarakat lokal sendiri. Bank Indonesia melalui kantor perwakilannya yang tersebar di seluruh wilayah/ provinsi yang ada di Indonesia, memiliki kebijakan tentang pemberdayaan masyarakat melalui pemberdayaan Usaha Mikro, Kecil dan Menengah yang tercantum 
dalam peraturan No.14/22/PBI/2012 Pasal 7 dan 8 mengenai bantuan teknis dalam rangka mendukung pengembangan Usaha Mikro, Kecil dan Menengah melalui penelitian, pelatihan, penyediaan informasi dan/atau fasilitasi.

Jenis-jenis pelatihan pemberdayaan yang diberikan Bank Indonesia kepada masyarakat itu berdasarkan hasil penelitian KPJU (Komoditas, Produk, Jasa usaha Unggulan) yang ada di setiap daerah yang tentunya masing-masing daerah memiliki potensi komoditas/produk unggulan yang berbeda-beda, seperti misalnya di Provinsi Gorontalo, berdasarkan hasil penelitian KPJU, salah satu produk yang harus dikembangkan adalah seni kerajinan karawo yang notabene adalah kerajinan leluhur asli Provinsi Gorontalo, yang awalnya masih kurang diperhatikan oleh pemerintah daerah setempat. Bank Indonesia merasa perlu untuk mengembangkan seni kerajinan tersebut agar dapat terus berkembang dan pada akhirnya akan memajukan perekonomian masyarakat Provinsi Gorontalo itu sendiri.

\section{METODE PENELITIAN}

Tempat penelitian adalah di Bank Indonesia Provinsi Gorontalo. Penelitian ini menggunakan metode evaluasi dan model evaluasi CIPP. Peneliti sengaja menggunakan metode evaluasi guna mengetahui hasil dari program pelatihan apakah berhasil baik atau tidak, dengan penggunaan metode evaluasi peneliti mengambil data dan membandingkan hasil pengumpulan data dengan kriteria atau standar yang digunakan, kriteria yang digunakan adalah kriteria umum.

\section{HASIL DAN PEMBAHASAN}

Kebijakan Bank Indonesia mengenai pemberdayaan masyarakat melalui UMKM, diatur dalam UU No.14/22/PBI/2012 pada bab IV pasal 7 dan 8 dijelaskan Bank Indonesia dapat memberikan bantuan teknis dalam rangka mendukung pengembangan Usaha Mikro, Kecil dan Menengah, dimana bantuan teknis itu dapat berupa : penelitian, pelatihan, penyediaan informasi; dan/ atau fasilitasi.

$$
\text { Peran Bank Indonesia dalam }
$$
pemberdayaan UMKM khususnya sulaman karawo adalah : (1) Melakukan penelitian KPJU (Komoditas Produk, Jasa usaha Unggulan) yang ada di Gorontalo guna penentuan pola klaster, dari hasil penelitian
KPJU akhirnya karawo lah yang kemudian dijadikan produk unggulan Gorontalo yang harus dikembangkan di Gorontalo. Dari hasil penelitian itulah kemudian Bank Indonesia membentuk program pemberdayaan yang difokuskan pada sulaman karawo yang kemudian dibentuk pola klaster karawo; (2) Menyelenggarakan pelatihan-pelatihan. Sejak tahun 2011 sampai dengan tahun 2013, Bank Indonesia telah banyak menyelenggarakan pelatihan-pelatihan, seperti pelatihan mengiris dan menyulam kain, pelatihan mendesain motif, pelatihan kewirausahaan, pelatihan menjahit, pelatihan pembukuan sederhana, pelatihan pengelolaan usaha; (3) Penyediaan Informasi, Bank Indonesia senantiasa memberikan informasi-informasi terkait pengembangan karawo, kegiatan yang dilakukan adalah publikasi baik melalui media massa lokal, juga melalui website antara lain kompas online. Selain itu, untuk memperluas akses informasi dan pemasaran terkait karawo, Bank Indonesia Gorontalo bekerjasama dengan pemerintah provinsi dan perbankan Gorontalo menginisiasi pelaksanaan Festival Karawo 2011 yang dilaksanakan pada tanggal 17-18 Desember 2011 bertempat di lapangan Taruna Kota Gorontalo. Kemudian pembuatan website www.tokokarawo.com dapat diakses apabila membutuhkan pesanan karawo secara online. Selain itu juga adanya penguatan kelembagaan pengrajin karawo melalui pembentukan kelompok pengrajin atau gabungan kelompok pengrajin setelah itu diadakan pendampingan dan bimbingan terhadap kelompok pengrajin binaan Bank Indonesia; (4) Fasilitasi. Bank Indonesia hingga saat ini telah memfasilitasi pengrajin kepada pihak Bank guna mendapatkan kemudahan untuk mendapatkan kredit modal, kemudian penguatan pasar produk bagi para pengrajin karawo, seperti pembuatan gerai karawo dan pembuatan website agar pemasaran produk karawo dapat dijalankan secara online.

Strategi pengembangan sulaman karawo diantaranya melalui keterpaduan dan sinergi program kerja dengan stakeholder terkait. Dari sekian banyak stakeholder terkait yang ada di wilayah Provinsi Gorontalo, tidak seluruhnya yang dapat dirangkul dalam menyusun rencana kerja sinergis. Beberapa upaya sinergi antara program pemberdayaan UMKM dan melalui Program Sosial Bank Indonesia (PSBI) dalam upaya pengembangan karawo telah dilakukan. Diharapkan pengrajin dan masyarakat Gorontalo dapat merasakan manfaatnya secara 
langsung. Diantara kegiatan PSBI yang didukung pengembangan karawo adalah sebagai berikut : (1) Upaya peningkatan promosi dan penjualan melalui pendirian dan perbaikan point of sales berupa gerai karawo yang dikelola oleh kelompok pengrajin; (2) Peningkatan edukasi masyarakat untuk mencintai karawo, upaya promosi dan peningkatan penjualan melalui penyelenggaraan festival karawo 2012.

Menurut hasil observasi peneliti, Bank Indonesia provinsi gorontalo telah melakukan penguatan kelembagaan dengan melakukan: (a) pembentukan 9 kelompok pengrajin karawo binaan bank indonesia yang tersebar di 4 wilayah kecamatan, yaitu kecamatan tapa, telaga, kota timur, dan batudaa pantai dan 3 kabupaten yaitu Kota Gorontalo, Kabupaten Gorontalo dan Kabupaten Bone bolango, yaitu kelompok pengrajin seruni, sumber usaha, kembang indah, isna taylor, raudatul jannah, mawar, mawar kencana, annisa dan nirwana; (b) pendampingan atau pembinaan pengrajin dan/ atau kelompok pengrajin karawo di Gorontalo melalui pertemuan dan koordinasi.

\section{KESIMPULAN}

Berdasarkan hasil penelitian, hasil persentase evaluasi context (kebijakan) memperoleh $95 \%$ dikategorikan sangat baik, evaluasi input (sumber daya) memperoleh 96,4\% dikategorikan sangat baik, evaluasi process (pelaksanaan) memperoleh $90 \%$ dikategorikan sangat baik, evaluasi product (dampak) memperoleh $75 \%$ dikategorikan cukup baik. Kemudian dari masing-masing hasil tersebut disimpulkan bahwa 93,3\% program pelatihan dikategorikan sangat baik.

Adapun saran-saran yang
direkomendasikan dalam penelitian ini adalah :

1. Pengembangan karawo perlu terus dikembangkan agar dapat diterima oleh semua kalangan dan menyesuaikan dengan perkembangan zaman. Hal yang dapat dilakukan antara lain peningkatan kompetensi pengrajin terkait perpaduan warna, pengkayaan motif, dan pengembangan tekhnik penggunaan jenis kain lain tidak hanya kain sutra, tafeta, sifon.

2. Pengembangan informasi dan pemasaran perlu terus dikaji dan dikembangkan untuk mendorong peningkatan omzet penjualan dan perluasan pasar bagi produk karawo sehingga mampu berbicara bukan hanya di tingkat lokal namun juga nasional bahkan internasional. Terkait dengan hal ini, publikasi dan pengkayaan informasi baik melalui Koran, website maupun sarana lainnya perlu terus dilakukan khususnya oleh dinas/ instansi terkait sebagai salah satu wujud kepedulian terhadap karawo.

3. Perlunya peningkatan peran pemerintah daerah dalam pengembangan karawo antara lain melalui sinergi program dan alokasi dana pada APBD

4. Perlunya peningkatan kepedulian pemerintah dan dinas terkait untuk pengembangan sulaman karawo, terutama perhatian terhadap upah pengrajin yang masih sangat rendah dan penstabilan harga bahan baku dengan memfasilitasi pengrajin untuk mendapatkan bahan baku dengan mudah dan murah.

5. Untuk memperkuat permodalan, perlu adanya penguatan kelompok pengrajin dan kemudahan mendapatkan kredit modal usaha di lembaga keuangan mikro.

\section{DAFTAR PUSTAKA}

Usman S. 2004. Pembangunan dan pemberdayaan masyarakat. Pustaka Pelajar. Yogyakarta. 